J Ästhet Chir 2010 · 3:122

DOI 10.1007/s12631-010-0087-y

C Springer-Verlag 2010

\author{
H.-G. Bull \\ St. Josefshospital Uerdingen, Krefeld
}

\title{
Jahrestagung der GÄCD
}

Sehr geehrte Frau Kollegin, Sehr geehrter Herr Kollege,

vom 21. bis zum 23. Oktober findet in Frankfurt unter der kollegialen Jahrespräsidentschaft von Herrn Prof. Dr. Kaufmann, Frau Dr. Wolters sowie Herrn Dr. Lampe, die 23. Jahrestagung der GÄCD statt.

Diese Jahrestagung steht unter dem Leitthema: „Ästhetische Chirurgie - eine interdisziplinäre Herausforderung".

\section{○ Der Jahreskongress der GÄCD findet vom 21. bis 23.10.2010 in Frankfurt am Main statt}

Nichts kann aus meiner Sicht besser unsere Gesellschaft charakterisieren als das Motto unseres diesjährigen Jahreskongresses. Die Jahrestagung stellt wie immer einen Höhepunkt des klinischen und wissenschaftlichen Austausches sowie der interdisziplinären Diskussion dar. Die bekannte Veranstaltungsform wurde in diesem Jahr etwas abgeändert. Anstatt der OP-Kurse und Seminare am Donnerstagnachmittag ist ein Assistentenforum geplant. Sinn dieses Forums ist es, den klinisch tätigen Nachwuchs der einzelnen Disziplinen mit ästhetischen Behandlungsmethoden und -möglichkeiten vertraut $\mathrm{zu}$ machen. Wir hoffen, dass von diesem Assistentenforum reger Gebrauch gemacht wird.
Bis zum Jahreskongress in Frankfurt wünsche ich Ihnen eine angenehme Sommerzeit und viel Freude und Gewinn bei der Lektüre dieser Ausgabe des Journal für Ästhetische Chirurgie.

Ihr

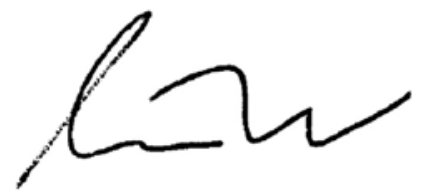

Prof. Dr. Dr. H.-G. Bull Schriftleiter Journal für Ästhetische Chirurgie

\section{Korrespondenzadresse}

Prof. Dr. Dr. H.-G. Bull

St. Josefshospital Uerdingen Kurfürstenstr. 69, 47829 Krefeld

bull.mkg@stjosef.de 